CARDIOVASCULAR MEDICINE

\title{
Risk factors for non-fatal myocardial infarction in young South Asian adults
}

\author{
J Ismail, T H Jafar, F H Jafary, F White, A M Faruqui, N Chaturvedi
}

Heart 2004;90:259-263. doi: 10.1136/hrt.2003.013631

See end of article for authors' affiliations

.....................

Correspondence to: Dr Tazeen H Jafar, Clinical Epidemiology Unit, Department of Community Health Sciences and Medicine, Aga Khan University, Stadium Road, Karachi, Pakistan; tazeen.jafar@aku.edu

Accepted 31 July 2003
Objective: To determine the risk factors for premature myocardial infarction among young South Asians. Design and setting: Case-control study in a hospital admitting unselected patients with non-fatal acute myocardial infarction.

Methods and subjects: Risk factor assessment was done in 193 subjects aged 15-45 years with a first acute myocardial infarct, and in 193 age, sex, and neighbourhood matched population based controls. Results: The mean (SD) age of the subjects was 39 (4.9) years and $326(84.5 \%)$ were male. Current smoking lodds ratio (OR) 3.82, 95\% confidence interval (Cl) 1.47 to 9.94), use of ghee (hydrogenated vegetable oil) in cooking (OR $3.91,95 \% \mathrm{Cl} 1.52$ to 10.03 ), raised fasting blood glucose (OR $3.32,95 \% \mathrm{Cl}$ 1.21 to 8.62 ), raised serum cholesterol (OR $1.67,95 \% \mathrm{Cl} 1.14$ to 2.45 for each $1.0 \mathrm{mmol} / \mathrm{l}$ increase), low income (OR 5.05, 95\% Cl 1.71 to 14.96), paternal history of cardiovascular disease (OR 4.84, 95\% CI 1.42 to 16.53 ), and parental consanguinity (OR $3.80,95 \% \mathrm{Cl} 1.13$ to 1.75 ) were all independent risk factors for acute myocardial infarction in young adults. Formal education versus no education had an independently protective effect on acute myocardial infarction (OR $0.04,95 \% \mathrm{Cl} 0.01$ to 0.35 ).

Conclusions: Tobacco use, ghee intake, raised fasting glucose, high cholesterol, paternal history of cardiovascular disease, low income, and low level of education are associated with premature acute myocardial infarction in South Asians. The association of parental consanguinity with acute myocardial infarction is reported for the first time and deserves further study.

\footnotetext{
C
} ardiovascular disease is a major global health problem reaching epidemic proportions. ${ }^{1}$ Low and middle income countries, including the South Asian countries of India and Pakistan, contribute significantly to the global burden of cardiovascular disease, accounting for $78 \%$ of all deaths and $86.3 \%$ of all loss of disability adjusted life years attributable to this cause. ${ }^{2}$

High risks of cardiovascular disease have been reported in South Asian populations, regardless of whether they live overseas or in their native countries. ${ }^{2-7}$ Epidemiological studies show that migrant populations of South Asian descent have higher risks of ischaemic heart disease than the native population. ${ }^{4} 8$ Moreover, coronary artery disease tends to emerge earlier in life, and thus mortality rate ratios are greatest in the youngest South Asians compared with other ethnic groups. ${ }^{89}$ However, acute myocardial infarction in young South Asians has not been extensively studied, and most of the existing data are on migrant South Asian populations. Furthermore, studies of migrant South Asians have focused on explanations for between-population differences, such as triglyceride and insulin resistance, rather than determining important risk factors within that population, which are not the same but are critical when considering disease prevention policies. We therefore conducted a casecontrol study of young individuals (aged 15-45 years) with a first myocardial infarct in Karachi, Pakistan, to determine the risk factors and the relative importance of these factors for acute myocardial infarction among young South Asians.

\section{METHODS \\ Subjects \\ Cases}

With their informed consent, we prospectively enrolled 193 consecutive patients aged 15-45 years who were admitted to the coronary care units of the National Institute of Cardiovascular Diseases and Liaquat National Hospital with acute myocardial infarction. Myocardial infarction was defined by the presence of at least two of the following ${ }^{10}$ :

- typical chest pain lasting at least 20 minutes

- an ECG showing ST elevation of at least $2 \mathrm{~mm}$ in two or more contiguous leads, with subsequent evolution of the changes

- diagnostic enzyme changes (doubling of creatine kinase with at least $10 \% \mathrm{MB}$ fraction).

Patients were excluded if they had a history of heart disease, clinical evidence of liver disease, were incapable of giving consent, or died within 24 hours of incident acute myocardial infarction. All cases were enrolled between August 2001 and June 2002.

\section{Controls}

An identical number of controls were selected from the neighbourhood of each case, after matching for age $( \pm 5$ years) and sex. The selection method involved identifying the house of the case subject and then flipping a coin to determine whether to turn right or left. The third house in the block adjacent to the case subject's house on the selected side was screened for an eligible control subject. If no control was found, adjacent houses were screened sequentially until an eligible control subject was recruited, after obtaining informed consent. Subjects were excluded if they had angina (Rose questionnaire); if they had history, clinical evidence, or ECG evidence of heart disease; if there was clinical evidence of liver disease; or if they were incapable of giving consent.

\section{Variables}

A detailed standardised questionnaire was developed using standard methods. In all participants, we recorded data on sociodemographic characteristics such as age, sex, marital status, occupation, monthly income, educational level, 
dietary pattern (based on food frequency questionnaire), physical activity, tobacco use, family history of heart disease, diabetes, consanguineous marriages, and known history of hypertension and diabetes. Anthropometric measurements including height, weight, waist circumference, and hip circumference were obtained. Waist circumference was measured at the narrowest diameter between the costal margin and the iliac crest. Hip circumference was measured at the greatest diameter over the buttock. Two readings of blood pressure were recorded in the supine position with a mercury sphygmomanometer. An ECG was done in all participants. Trained research assistants carried out all measurements using standardised protocols.

Fasting blood glucose and lipids were measured within 24 hours of admission of the case subjects, and in all control subjects. Blood samples of all participants were sent to the Aga Khan University Hospital laboratory.

Ethical approval was obtained from the ethics review committee, Aga Khan University, Karachi.

\section{Statistical analysis}

Comparison of continuous (mean) and discrete variables was done between cases and controls. Stepwise conditional logistic regression analysis was carried out using forward selection with inclusion probability $(p)$ value of 0.2 , after matching of cases with controls for continuous variables (body mass index, waist-hip ratio, systolic and diastolic blood pressures, and fasting blood cholesterol) and for categorical variables (current smoking, proportion with raised blood glucose (fasting blood glucose $\geqslant 6.1 \mathrm{mmol} / \mathrm{l}$ ), ${ }^{11}$ history of diabetes, hypertension, education status, income level, use of ghee (clarified butter) in cooking, meat consumption, physical activity, parental consanguinity, and paternal and maternal history of cardiovascular disease). Estimates of odds ratios (OR) and 95\% confidence intervals (CI) were made. Interaction terms between variables were tested for significance. SAS statistical software (SAS Institute Inc, Cary, North Carolina, USA) was used for all analyses. Probability values were two tailed.

\section{RESULTS}

The response rate was 100\% for cases and $96.5 \%$ for controls. In all, 388 subjects were recruited (194 cases and 194 controls). One patient died on the third day of admission before complete data were obtained, and so one subject each from the case and control groups was excluded from the analysis.

The demographic characteristics of the subjects are shown in table 1. Their mean (SD) age was 39 (4.9) years (range 1545 years) and $84.5 \%$ were male. Compared with the controls, cases were more likely to use ghee (hydrogenated vegetable oil) in cooking $(54.4 \% v 21.2 \%, \mathrm{p}=0.001)$, to smoke $(51.8 \% \vee 21.2 \%, \mathrm{p}=0.001)$, to have parents who were also first cousins (parental consanguinity) (34.2\% $v \quad 18.6 \%$, $\mathrm{p}=0.001)$, to have a lower income $(73.6 \% v 50.6 \%$, $\mathrm{p}=0.001)$, to have a lower education level $(5.1 \% v 31.6 \%$, $\mathrm{p}=0.001$ had formal school education), to have a raised blood glucose $(38.9 \% \vee 24.4 \%, p=0.001)$, and to have raised mean cholesterol concentrations (5.1 $v 4.5 \mathrm{mmol} / \mathrm{l}$, $\mathrm{p}<0.001)$.

The unadjusted odds ratios (with 95\% confidence intervals) for factors associated with acute myocardial infarction are shown in table 2. In the univariate analyses, current smoking, raised blood glucose, raised blood cholesterol, parental first cousin marriage, use of ghee in cooking, lack of education, and low income level ( $\mathrm{p}<0.001$ for each), and paternal history of myocardial infarction $(p=0.03)$, were all associated with a higher risk of acute myocardial infarction.
Table 3 shows a comparison of smoking characteristics between the cases and the controls. In all, 141 subjects $(36.5 \%)$ were current smokers: $100(51.8 \%)$ in the case group and $41(21.2 \%)$ in the control group $(\mathrm{p}=0.001)$. There was a higher proportion of heavy smokers ( $\geqslant 10$ cigarettes a day) among cases than controls ( $36.8 v 10.4 \%)$. The average age at which subjects started smoking was younger in cases than in controls ( $18.8 \vee 21.9$ years, respectively, $\mathrm{p}<0.001$ ).

The predictive independent variables identified in the stepwise multivariate conditional regression analysis were: lack of education $(p<0.001)$; use of ghee in cooking $(p<0.001)$; raised blood glucose $(p<0.001)$; current smoking ( $p=0.001)$; low income $(p=0.002)$; raised blood cholesterol $(\mathrm{p}=0.005)$; paternal history of cardiovascular disease $(p=0.01)$; and first cousin marriage $(p=0.04)$. The adjusted odds ratios (95\% CI) for factors associated with acute myocardial infarction are shown in table 2.

No significant interactions were detected among the variables for risk of acute myocardial infarction. Analysis was repeated using unmatched logistic regression analysis. The overall results remained unchanged.

\section{DISCUSSION}

This is the first reported case-control study aimed at identifying the risk factors for acute myocardial infarction in young South Asian adults ( $\leqslant 45$ years) from Karachi. We found that smoking, the use of ghee in cooking, raised blood glucose and cholesterol, parental consanguinity, paternal history of cardiovascular disease, low level of income, and lack of education were all independent risk factors for acute myocardial infarction in young South Asian adults.

Our study was conducted in institutions which are renowned for providing first line cardiac care to urban and suburban populations from all socioeconomic strata in Karachi, the most populous city of Pakistan. Our criteria for the diagnosis of acute myocardial infarction were stringent and the cases were not known to have had previous heart disease. This avoids the possibility of misdiagnosis of cases identified by the sole use of ECG. Further, our method of randomly selecting age and sex matched controls from the residential neighbourhoods of the case subjects minimises selection bias and reduces confounding by other identified and unidentified factors related to socioeconomic status.

Population surveys indicate that around two thirds of marriages in Pakistan are consanguineous. ${ }^{12}{ }^{13}$ There are controversial data on whether consanguineous marriages lead to a higher incidence of congenital and acquired diseases in the offspring. ${ }^{14}{ }^{15}$ Our study is the first to report a relation between parental consanguinity and early myocardial infarction, independent of family history of cardiovascular disease. It is reasonable to speculate that consanguinity increases the likelihood of inheriting genetic factors-identified as well as unidentified-leading to premature ischaemic heart disease. However, environmental factors such as dietary patterns are more likely to be shared among family members, and this effect will probably be stronger in consanguineous relationships. Further studies are needed to confirm this. If found to be true, one could speculate that consanguinity has a confounding effect on the risk factors thought to be specific to the South Asian population.

Countries like India, Pakistan, and Bangladesh, where consanguineous marriages are very common (15-66\%), are home to over one sixth of the world's population. ${ }^{12} 131617$ These countries are major contributors to the global burden of cardiovascular disease at present, and their contribution is projected to grow, given their consistent population growth rates. ${ }^{1}$ Furthermore, the practice of consanguinity is also observed in migrant South Asian populations in the West as well as in native populations in the Middle East, ${ }^{18}$ China, ${ }^{19}$ 
Table 1 Comparison of characteristics between cases and controls

\begin{tabular}{|c|c|c|c|c|}
\hline Variable & Total & Cases & Controls & p Value \\
\hline Number of patients & 386 & 193 & 193 & \\
\hline Male & $326(84.5 \%)$ & $163(84.5 \%)$ & $163(84.5 \%)$ & 0.99 \\
\hline Age (years) & $39.0(4.9)$ & $39.3(5.1)$ & $38.7(4.7)$ & 0.29 \\
\hline Weight $(\mathrm{kg})$ & $69.3(12.7)$ & $68.9(12.5)$ & $69.8(12.9)$ & 0.51 \\
\hline Body mass index $\left(\mathrm{kg} / \mathrm{m}^{2}\right)$ & $24.9(4.7)^{\prime}$ & $24.9(4.4)$ & $24.8(5.0)$ & 0.97 \\
\hline *Overweight & $178(46.1 \%)$ & $97(50.3 \%)$ & $81(41.9 \%)$ & 0.10 \\
\hline †Obese & $39(10.1 \%)$ & $21(10.9 \%)$ & $18(19.3 \%)$ & 0.61 \\
\hline Waist-hip ratio & $0.93(0.1)$ & $0.93(0.1)$ & $0.93(0.1)$ & 0.97 \\
\hline Systolic BP (mm Hg) & $120.1(17.1)$ & $118.5(18.1)$ & $122.6(15.9)$ & 0.02 \\
\hline Diastolic BP $(\mathrm{mm} \mathrm{Hg})$ & $78.3(17.2)$ & $78.1(22.0)$ & $78.6(10.5)$ & 0.77 \\
\hline Fasting blood glucose (mmol/l) & $7.2(4.2)$ & $8.1(5.2)$ & $6.6(3.2)$ & 0.001 \\
\hline ‡Raised blood glucose & $122(31.6 \%)$ & $75(38.9 \%)$ & $47(24.4 \%)$ & 0.001 \\
\hline Serum cholesterol (mmol/l) & $4.8(1.9)$ & $5.1(1.3)$ & $4.5(1.0)$ & $<0.001$ \\
\hline §Raised blood cholesterol & $112(30.2 \%)$ & $75(38.9 \%)$ & $37(19.2 \%)$ & 0.001 \\
\hline Illicit drug use & $14(3.7 \%)$ & $8(4.2 \%)$ & $6(3.2 \%)$ & 0.60 \\
\hline Ghee in cooking & $146(37.8 \%)$ & $105(54.4 \%)$ & $41(21.2 \%)$ & 0.001 \\
\hline - Beef or mutton eaters & $320(82.9 \%)$ & $165(85.5 \%)$ & $155(80.3 \%)$ & 0.18 \\
\hline **Parental consanguinity & $102(26.4 \%)$ & $66(34.2 \%)$ & $36(18.6 \%)$ & 0.001 \\
\hline ††Paternal history of CVD & $80(21.2 \%)$ & $48(24.9 \%)$ & $32(16.6 \%)$ & 0.05 \\
\hline ††Maternal history of CVD & $83(22.1 \%)$ & $44(22.8 \%)$ & $39(20.2 \%)$ & 0.47 \\
\hline History of hypertension & $61(15.8 \%)$ & $27(14.0 \%)$ & $34(17.7 \%)$ & 0.21 \\
\hline History of diabetes & $37(9.6 \%)$ & $13(6.7 \%)$ & $24(12 . \% 5)$ & 0.06 \\
\hline$\ddagger \ddagger$ Monthly income $\leqslant$ Rs 5000 & $239(61.9 \%)$ & $142(73.6 \%)$ & $97(50.3 \%)$ & 0.001 \\
\hline Level of education & & & & 0.001 \\
\hline None & 71 (18.4\%) & $61(31.6 \%)$ & $10(5.1 \%)$ & \\
\hline School & $198(51.3 \%)$ & $96(49.8 \%)$ & $104(52.9 \%)$ & \\
\hline College & $117(30.3 \%)$ & $36(18.7 \%)$ & $84(42.4 \%)$ & \\
\hline$\S \S$ Exercise & $67(17.4 \%)$ & 41 (21.2\%) & $26(13.5 \%)$ & 0.05 \\
\hline Married (\%) & $341(88.5)$ & $170(88.1)$ & $171(89.1)$ & 0.85 \\
\hline \multicolumn{5}{|c|}{ 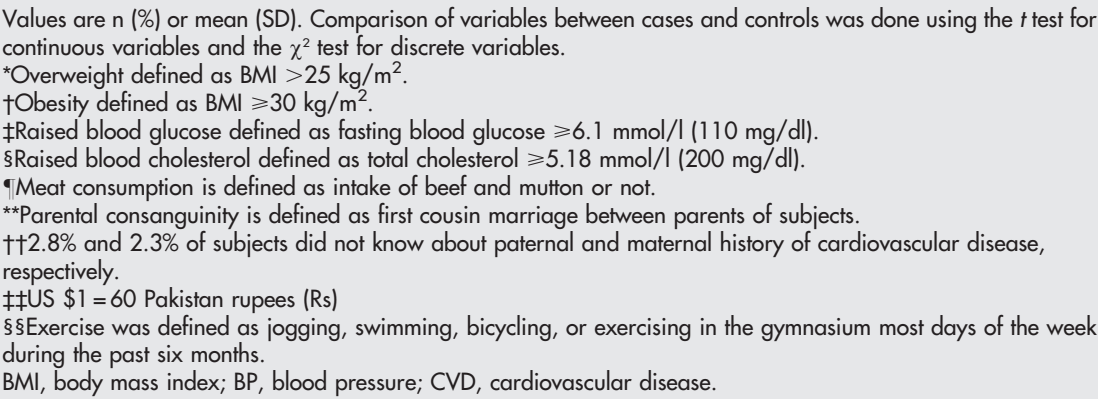 } \\
\hline
\end{tabular}

Turkey, ${ }^{20}$ and Africa. ${ }^{21}$ The association of consanguinity and premature heart disease needs to be studied in these populous nations as well as in cross-population ethnic studies.

Our study highlights the relative importance of potentially modifiable risk factors for acute myocardial infarction in the young population of Pakistan. Smoking - an established risk factor for acute myocardial infarction-is associated with endothelial dysfunction and can precipitate coronary spasm..$^{22}$ Thus smoking can contribute to myocardial infarction even in subjects with minimal atherosclerosis. In our study, the odds ratio for acute myocardial infarction in current smokers was 3.82 (95\% CI 1.47 to 9.94) compared with current nonsmokers. As shown in table 3, the risk was higher in those who smoked heavily. Further, there was a significant difference in the age of initiation of smoking between cases ( 18.8 years) and controls $(21.9$ years $)(p<0.001)$. Owing to increased restrictions in the industrialised countries, the marketing strategies of tobacco companies are now targeting the adolescent population in developing countries. $^{23} 24$ Our findings emphasise the need for antitobacco campaigns to target children and young adults, and strict legislation against advertising cigarettes for this vulnerable population.

Saturated fat intake has been related to acute myocardial infarction in adults. ${ }^{25}$ Ghee contains cholesterol oxides that are thought to be related to atherosclerosis. ${ }^{26}$ In adipose tissue of subjects who use ghee for cooking compared with other types of non-hydrogenated oils, a higher percentage of trans fatty acids, known to increase the risk of ischaemic heart disease, ${ }^{27}$ has been reported. ${ }^{28}$ Although previous studies in South Asian populations indicate a high consumption of ghee in India and Pakistan, data for an independent relation between ghee and cardiovascular disease in the same population are conflicting. ${ }^{79} 30$ The production of ghee has been rising sharply in Pakistan. ${ }^{31}{ }^{32}$ Ours is the first study to show an independent association between ghee consumption and acute myocardial infarction. We found a high risk of infarction in young Pakistani adults attributable to ghee (adjusted relative risk 3.92, 95\% CI 1.52 to 10.03). A high prevalence of ghee consumption has also been reported in migrant South Asians living in the West.. ${ }^{33}$ Our findings suggest that ghee consumption is a potential target for preventive strategies.

The association between a low level of education and acute myocardial infarction has been reported previously in other populations. ${ }^{34}{ }^{35}$ It is speculated that high risk behaviours contributing to cardiovascular disease are more common in individuals with low levels of education. ${ }^{36}$ We found that subjects who did not attend school were at higher risk of acute myocardial infarction than those who did. Our findings also suggest that this association is not entirely related to the conventional risk factors including smoking, ghee, low income, and level of physical activity. Thus other psychosocial behaviours associated with lack of education are likely to be responsible for this relation. 
Table 2 Unadjusted and adjusted risk of acute myocardial infarction

\begin{tabular}{|c|c|c|}
\hline & Unadjusted odds ratio $(95 \% \mathrm{CI})$ & ${ }^{*}$ Adjusted odds ratio $(95 \% \mathrm{Cl})$ \\
\hline Current $v$ non-current smoker & $4.22(2.53$ to 7.06$)$ & $3.82(1.47$ to 9.94$)$ \\
\hline Ghee $v$ no ghee in cooking & 4.94 (2.89 to 8.45$)$ & $3.91(1.52$ to 10.03$)$ \\
\hline †Raised $v$ normal blood glucose & 4.00 (2.27 to 7.04$)$ & $3.23(1.21$ to 8.62$)$ \\
\hline Blood cholesterol & $\begin{array}{l}1.57(1.28 \text { to } 1.93) \text {, for } \\
\text { each } 1.0 \mathrm{mmol} / \mathrm{l} \text { increase }\end{array}$ & $\begin{array}{l}1.67(1.14 \text { to } 2.45) \text {, for each } \\
1.0 \mathrm{mmol} / / \text { increase }\end{array}$ \\
\hline Mean systolic blood pressure & $1.02(1.00$ to 1.03$)$ & †NS \\
\hline Mean diastolic blood pressure & $1.00(0.99$ to 1.01$)$ & NS \\
\hline $\begin{array}{l}\text { §arental consanguinity } v \text { no } \\
\text { consanguinity }\end{array}$ & $2.43(1.46$ to 4.04$)$ & $3.80(1.13$ to 12.75$)$ \\
\hline Formal schooling $v$ no school & $0.06(0.02$ to 0.17$)$ & $0.04(0.01$ to 0.35$)$ \\
\hline Consume meat & 1.50 (0.85 to 2.64$)$ & NS \\
\hline $\begin{array}{l}\text { Monthly income less than } \\
v \text { more than Rs } 5000\end{array}$ & 1.81 (1.06 to 3.08 ) & 5.05 (1.71 to 14.96$)$ \\
\hline Body mass index & $\begin{array}{l}1.00(0.96 \text { to } 1.05) \text {, for } \\
\text { each unit increase }\end{array}$ & NS \\
\hline Waist-hip ratio (SD) & $\begin{array}{l}0.97(0.07 \text { to } 13.13) \text {, for } \\
\text { each unit increase }\end{array}$ & NS \\
\hline Illicit drug use & $0.75(0.26$ to 2.16$)$ & NS \\
\hline $\begin{array}{l}\text { Paternal history of CVD v no } \\
\text { paternal history of CVD }\end{array}$ & 1.81 (1.06 to 3.08 ) & 4.84 (1.42 to 16.53$)$ \\
\hline $\begin{array}{l}\text { Maternal history of CVD v no } \\
\text { maternal history of CVD }\end{array}$ & $1.17(0.72$ to 1.90$)$ & $1.33(0.43$ to 4.08$)$ \\
\hline $\begin{array}{l}\text { History of hypertension } v \text { no } \\
\text { history of hypertension }\end{array}$ & $0.67(0.38$ to 1.17$)$ & NS \\
\hline $\begin{array}{l}\text { History of diabetes } v \text { no } \\
\text { history of diabetes }\end{array}$ & $0.50(0.24$ to 1.03$)$ & NS \\
\hline -Exercise $v$ no exercise & 1.75 (1.01 to 3.03$)$ & $1.89(0.52$ to 6.85$)$ \\
\hline Married $v$ unmarried & $1.00(0.51$ to 1.96$)$ & NS \\
\hline \multicolumn{3}{|c|}{$\begin{array}{l}\text { *Adjusted odds ratios are based on multivariable model. } \\
\text { †Raised blood glucose defined as fasting blood glucose } \geqslant 6.1 \mathrm{mmol} / \mathrm{l}(110 \mathrm{mg} / \mathrm{dll}) \text {. } \\
\text { †NS: these factors were not significantly associated with acute myocardial infarction in the multivariable model and } \\
\text { were therefore not included in the final model. } \\
\text { §Parental consanguinity is defined as first cousin marriage between parents of subjects. } \\
\text {-Exercise was defined as jogging, swimming, bicycling or exercising in the gymnasium most days of the week } \\
\text { during the past six months. } \\
\mathrm{Cl} \text {, confidence interval; CVD, cardiovascular disease. }\end{array}$} \\
\hline
\end{tabular}

We did not find a correlation between central obesity, meat consumption, physical inactivity, and acute myocardial infarction. ${ }^{37}$ It is possible that the broad prevalence of these risk factors in the entire study population limited their recognition as an aetiological agent in a population study. ${ }^{38}$ It is also important to emphasise that failure to detect an association between these risk factors and acute myocardial infarction in a young South Asian population does not mean that these are not important factors in South Asians compared with other populations.

Our study has various limitations. We did not measure all the possible risk factors for acute myocardial infarction, such as the fractionated lipid profile, emerging risk factors like serum homocysteine and fibrinogen concentrations, and psychosocial factors such as stress and anger. ${ }^{36}{ }^{39}$ However, we did measure blood cholesterol and most other modifiable conventional risk factors for acute myocardial infarction. Further, as compared with other populations, people of South Asian descent are known to have an excess of certain cardiovascular risk factors such as insulin resistance and abnormal triglyceride values. ${ }^{40}$ However, that does not necessarily translate into a South Asian group effect. We do not believe that our findings are biased by failure to account for these factors, though they would, no doubt, be important to examine in a study comparing populations.

We did not detect any interactions between the factors associated with risk of acute myocardial infarction. Studying these factors in a much larger sample could shed more light on the possible complex interrelations among them. However, our study has the largest sample of young South Asians with acute myocardial infarction reported so far. The study was not designed to estimate the proportion of patients who die within 24 hours of acute myocardial infarction, or to study the risk factors associated with fatal acute infarction. However, the high response rate in our study increases the likelihood of our results being generalisable to patients with non-fatal acute myocardial infarction. Finally, while this study does not establish a cause-effect relation between the

Table 3 Smoking and the risk of acute myocardial infarction

\begin{tabular}{lllll}
\hline Variable & Total & Cases & Controls & *Unadjusted odds ratio (95\% Cl) \\
\hline Never smoked & $207(53.6)$ & $69(35.8)$ & $138(71.5)$ & 1.00 \\
Former smoker & $38(9.7)$ & $24(12.4)$ & $14(7.3)$ & $5.89(2.43$ to 14.27$)$ \\
Current smoker & $141(36.5)$ & $100(51.8)$ & $41(21.2)$ & $6.85(3.66$ to 12.81$)$ \\
$1-10$ cigarettes/day & $37(9.5)$ & $17(8.8)$ & $20(10.4)$ & $1.89(0.87$ to 4.09$)$ \\
$>10$ cigarettes/day & $91(23.3)$ & $71(36.8)$ & $20(10.4)$ & $6.44(3.36$ to 12.35$)$ \\
Age (years) when started & $19.7(5.7)$ & $18.8(5.6)$ & $21.9(6.1)$ & $0.73(0.57$ to 0.95$)$ for each year \\
smoking & & & & increase in age \\
\hline
\end{tabular}

Values are $\mathrm{n}(\%)$.

*Odds ratios for acute myocardial infarction were computed using logistic regression after matching cases with controls. Reference group was never-smokers (never smoked at any time). 
identified risk factors and premature heart disease, it raises the possibility that several of the associated factors may be modifiable risk factors for acute myocardial infarction.

Based on our findings, we suggest that stringent tobacco control programmes, legislation to restrict the production of ghee, the promotion of exercise and other lifestyle and dietary measures to improve glucose tolerance ${ }^{41}$ cholesterol screening programmes, and improving the level of education are likely to have a profound effect on the burden of premature ischaemic heart disease in South Asians. The relation between parental consanguineous marriages and acute myocardial infarction needs further study.

\section{ACKNOWLEDGEMENTS}

Supported by grant from the University Research Council, Aga Khan University, Karachi, Pakistan.

\section{Authors' affiliations}

J Ismail, T H Jafar*, F White, Clinical Epidemiology Unit, Department of Community Health Sciences, Aga Khan University, Karachi, Pakistan

F H Jafary, Section of Cardiology, Department of Medicine, Aga Khan University

A M Faruqui, National Institute of Cardiovascular Diseases, Karachi, Pakistan

N Chaturvedi, Department of Epidemiology and Public Health, Imperial College of Medicine at St Mary's, London, UK

*Also Department of Medicine, Aga Khan University, and New England Medical Center, Tufts University School Medicine, Boston, Massachusetts, USA

\section{REFERENCES}

1 WHO. Disease statistics. World Health Report 1999. Mortality by sex, cause and WHO regions, estimates for 1998. Geneva: World Health Organisation, 1999.

2 WHO. The World Health Report 1999. Making a difference. Geneva: World Health Organisation, 1999.

3 Chadha SL, Radhakrishnan S, Ramachandran K, et al. Epidemiological study of coronary heart disease in urban population of Delhi. Indian J Med Res 1990;92:424-30

4 McKeigue PM, Miller GJ, Marmot MG. Coronary heart disease in south Asians overseas: a review. J Clin Epidemiol 1989;42:597-609.

5 Balarajan R. Ethnic differences in mortality from ischaemic heart disease and cerebrovascular disease in England and Wales. BMJ 1991;302:560-4.

6 Enas EA, Yusuf S, Mehta JL. Prevalence of coronary artery disease in Asian Indians. Am J Cardiol 1992;70:945-9.

7 Pais $\mathbf{P}$, Pogue J, Gerstein $\mathrm{H}$, et al. Risk factors for acute myocardial infarction in Indians: a case-control study. Lancet 1996;348:358-63.

8 Reddy KS, Yusuf S. Emerging epidemic of cardiovascular disease in developing countries. Circulation 1998;97:596-601.

9 Anand SS, Yusuf S, Vuksan V, et al. Differences in risk factors, atherosclerosis, and cardiovascular disease between ethnic groups in Canada: the study of health assessment and risk in ethnic groups (SHARE). Lancet 2000;356:279-84.

10 Ryan TJ, Anderson JL, Antman EM, et al. ACC/AHA guidelines for the management of patients with acute myocardial infarction. A report of the American College of Cardiology/American Heart Association task force on practice guidelines (committee on management of acute myocardial infarction). J Am Coll Cardiol 1996;28:1328-428.

11 American Diabetes Association: clinical practice recommendations 1997. Diabetes Care 1997;20(suppl 1):S1-70.

12 Hussain R. Community perceptions of reasons for preference for consanguineous marriages in Pakistan. J Biosoc Sci 1999;31:449-61.
13 Hussain R, Bittles $\mathrm{AH}$. Consanguineous marriage and differentials in age at marriage, contraceptive use and fertility in Pakistan. J Biosoc Sci 1999;31:121-38

14 Ulusoy M, Tuncbilek E. Consanguineous marriage in Turkey and its effects on infant mortality. Nufusbil Derg 1987;9:7-26.

15 Modell B, Darr A. Science and society: genetic counselling and customary consanguineous marriage. Nat Rev Genet 2002;3:225-9.

16 Durkin MS, Khan NZ, Davidson LL, et al. Prenatal and postnatal risk factors for mental retardation among children in Bangladesh. Am J Epidemiol 2000; 152:1024-33.

17 Ramesh A, Srikumari CR, Sukumar S. Parallel cousin marriages in Madras, Tamil Nadu: new trends in Dravidian kinship. Soc Biol 1989;36:248-54.

18 al-Abdulkareem AA, Ballal SG. Consanguineous marriage in an urban area of Saudi Arabia: rates and adverse health effects on the offspring. J Community Health 1998;23:75-83.

19 Zhang JX. Effects of consanguineous marriages on hereditary diseases: a study of the Han ethnic group in different geographic districts of Zhejiang Province. Zhonghua Yi Xue Za Zhi 1992;72:674-6, 703.

20 Hancioglu A, Akadli Ergocmen B. Some social aspects of Turkish marital unions and their relationship with early age mortality. Nufusbil Derg 1992; 14:3-25

21 Hampshire KR. Consanguineous marriage among the Fulani. Hum Biol 2001;73:597-603.

22 Choudhury L, Marsh JD. Myocardial infarction in young patients. Am J Med $1999 ; 107: 254-61$

23 Chelala C. Tobacco corporations step up invasion of developing countries. Lancet 1998;351:889.

24 Gray N. Tobacco industry and EC advertising ban. Lancet 2002;359:1264-5.

25 Caggiula AW, Mustad VA. Effects of dietary fat and fatty acids on coronary artery disease risk and total and lipoprotein cholesterol concentrations: epidemiologic studies. Am J Clin Nutr 1997;65(suppl 5):1597-610S.

26 Jacobson MS. Cholesterol oxides in Indian ghee: possible cause of unexplained high risk of atherosclerosis in Indian immigrant populations. Lancet 1987;ii:656-8.

27 Willett WC, Ascherio A. Trans fatty acids: are the effects only marginal? Am J Public Health 1994;84:722-4.

28 Ascherio A, Cho E, Walsh K, et al. Premature coronary deaths in Asians. BMJ 1996;312:508

29 Singh RB, Niaz MA, Ghosh S, et al. Association of trans fatty acids (vegetable ghee) and clarified butter (Indian ghee) intake with higher risk of coronary artery disease in rural and urban populations with low fat consumption. Int J Cardiol 1996;56:289-98, discussion 299-300.

30 Jafar TH, Levey AS, Jafary FH, et al. Ethnic subgroup differences in hypertension in Pakistan. J Hypertens 2003;21:905-12.

31 Faruqui A. Heart disease in South Asia: experiences in Pakistan. In: Hurst JW ed. Clinical essays on heart. Vol 1. Heart disease and geography. New York: McGraw Hill, 1983.

32 State Bank of Pakistan. Annual report. Karachi, Pakistan, 1980-1.

33 Lip GY, Malik I, Luscombe C, et al. Dietary fat purchasing habits in whites, blacks and Asian peoples in England - implications for heart disease prevention. Int J Cardiol 1995:48:287-93.

34 Shea S, Stein $A D$, Basch $C E$, et al. Independent associations of educational attainment and ethnicity with behavioral risk factors for cardiovascular disease. Am J Epidemiol 1991;134:567-82.

35 Bobak M, Hertzman C, Skodova Z, et al. Own education, current conditions, parental material circumstances, and risk of myocardial infarction in a former communist country. J Epidemiol Community Health 2000;54:91-6.

36 Mittleman MA, Maclure M, Nachnani M, et al. Educational attainment, anger, and the risk of triggering myocardial infarction onset. The determinants of myocardial infarction onset study investigators. Arch Intern Med 1997; 157:769-75

37 McKeigue PM, Shah B, Marmot MG. Relation of central obesity and insulin resistance with high diabetes prevalence and cardiovascular risk in South Asians. Lancet 1991;337:382-6.

38 Rose G. Sick individuals and sick populations. Int J Epidemiol 1985;14:32-8

39 Scaglione L, Bergerone S, Gambino R, et al. Role of lipid, apolipoprotein levels and apolipoprotein E genotype in young Italian patients with myocardia infarction. Nutr Metab Cardiovasc Dis 1999;9:118-24.

40 McKeigue PM, Ferrie JE, Pierpoint T, et al. Association of early-onset coronary heart disease in South Asian men with glucose intolerance and hyperinsulinemia. Circulation 1993;87:152-61.

41 Tuomilehto J, Lindstrom J, Eriksson JG, et al. Prevention of type 2 diabetes mellitus by changes in lifestyle among subjects with impaired glucose tolerance. N Engl J Med 2001;344:1343-50. 